This PDF is a selection from an out-of-print volume from the National Bureau of Economic Research

Volume Title: Behavioral and Distributional Effects of Environmental Policy

Volume Author/Editor: Carlo Carraro and Gilbert E. Metcalf, editors

Volume Publisher: University of Chicago Press

Volume ISBN: 0-226-09481-2

Volume URL: http://www.nber.org/books/carr01-1

Conference Date: June 11âf“"12, 1999

Publication Date: January 2001

Chapter Title: The Effects of Environmental Policy on the Performance of Environmental Research Joint Ventures

Chapter Author: Yannis Katsoulacos, Alistair Ulph, David Ulph

Chapter URL: http://www.nber.org/chapters/c10613

Chapter pages in book: (p. 309 - 346) 


\title{
The Effects of Environmental Policy on the Performance of Environmental Research Joint Ventures
}

\author{
Yannis Katsoulacos, Alistair Ulph, and David Ulph
}

Over the last 10 years, a significant literature has developed on the effects of environmental policy on the incentives for firms to undertake research and development (R\&D) that will lead to the development of new environmentally friendly products and/or processes. In what follows, we refer to this as environmental R\&D.

The starting point of this literature is the recognition that market forces will produce very weak incentives for firms to undertake environmental $\mathrm{R} \& \mathrm{D}$, and so government incentives are required to correct this market failure. There have been three main strands in this literature. The first ${ }^{1} \mathrm{ex}^{-}$ amines the effects of environmental policy (e.g., taxes and standards) on the incentives to undertake R\&D. An important point that emerges from this literature is that while environmental policy does indeed give firms an incentive to undertake environmental $\mathrm{R} \& \mathrm{D}$, a toughening of this policy will not necessarily increase the amount of R\&D. This is because while a tougher environmental policy will have a direct effect of encouraging more environmental R\&D, it can also have the indirect effect of raising costs and reducing output, and this will lower R\&D incentives. Thus, contrary to the widely discussed Porter hypothesis, there is no theoretical presump-

Yannis Katsoulacos is professor of economics at the Athens University of Economics and Business. Alistair Ulph is deputy vice-chancellor and professor of economics at the University of Southampton. He is currently president of the European Association of Environmental and Resource Economists. David Ulph is professor of economics and executive director of the ESRC Centre for Economic Learning and Social Evolution (ELSE) at University College London.

The authors are grateful for the insightful comments of the discussant, Jerome Rothenberg, and of Gilbert Metcalf, Carlo Carraro, Sjak Smulders, John Whalley, and other conference participants.

1. See Ulph (1997) for a survey. 
tion that tougher environmental policy will itself be sufficient to promote greater $\mathrm{R} \& \mathrm{D}$ incentives.

A second strand ${ }^{2}$ looks at the combined effects of both technology policy and environmental policy on the levels of $\mathrm{R} \& \mathrm{D}$, output, and emissions in an oligopolistic industry. Thus, in the context of a model where firms do only environmental R\&D, Katsoulacos and Xepapadeas (1996) show that a combined R\&D subsidy plus emissions tax can generate the firstbest solution. Petrakis and Poyago-Theotoky (1997) explore the design of technology policy in the context where governments are constrained in the use of environmental policy.

The third strand ${ }^{3}$ considers the setting of environmental policy in a multinational context, where governments are aware that the levels of environmental policies they set will affect the strategic competition between firms - particularly their choices of R\&D. The issue here is whether trade concerns lead governments to set environmental policies that are too lax.

A feature of virtually all ${ }^{4}$ this literature is that it assumes that firms undertake $\mathrm{R} \& \mathrm{D}$ in a noncooperative fashion. However, there are many potential benefits that are thought to flow from having firms undertake $\mathrm{R} \& \mathrm{D}$ cooperatively in a research joint venture (RJV): a reduction in risk, the achievement of economies of scale and scope, the elimination of wasteful duplication, and the greater appropriation of the returns to innovation. These benefits arise because RJVs are thought to promote greater information sharing and coordination of R\&D decisions. ${ }^{5}$

There is now a considerable literature on the performance of RJVs. However, this literature focuses exclusively on the types of product and process $\mathrm{R} \& \mathrm{D}$ that firms undertake for conventional commercial benefit and, as such, ignores environmental innovation, which, as we have pointed out, is primarily undertaken in response to environmental policies. ${ }^{6}$ Consequently, in this paper we wish to understand how environmental policy affects environmental innovation when we allow for the possibility that this innovation is undertaken cooperatively through the formation of what

2. See, e.g., Katsoulacos and Xepapadeas (1996) and Petrakis and Poyago-Theotoky (1997).

3. See e.g. A. Ulph (1996a, 1996b), Ulph and Ulph (1996), and D. Ulph (1994).

4. The exception is Petrakis and Poyago-Theotoky (1997). However, although they allow for $\mathrm{R} \& \mathrm{D}$ cooperation, they assume that governments are unable to implement environmental policies such as pollution taxes. Thus they are unable to address the central issue of this paper - the effects of environmental policies on RJV performance.

5. Of course, concern is also sometimes expressed that RJVs may use the ability to cooperate on R\&D decisions to promote anticompetitive practices in the output market. Nevertheless, RJVs are widely thought to be beneficial on balance, and many governments promote their formation through reducing the ventures' antitrust liabilities, and, sometimes, by subsidizing R\&D undertaken through an RJV. For an account of recent work on this topic, see, e.g., Poyago-Theotoky (1997) for a collection of recent papers.

6. These may be actual or anticipated environmental regulatory policies. Scott (1996) reports evidence that RJV formation takes place in response to both actual and anticipated regulation. 
we will call environmental RJVs. In particular, we wish to understand how environmental policy affects the innovative performance of RJVs as compared to a noncooperative equilibrium.

The plan of the paper is as follows. In section 10.1, we set out some background discussion on the current understanding of RJV performance and sketch out the issues that need to be addressed in thinking about the interaction between environmental policy and the performance of environmental RJVs. In section 10.2 we set out a formal model that captures these issues. Section 10.3 uses the model to provide an analysis of the links between environmental policy and the performance of RJVs. Section 10.4 concludes.

Before we proceed, it is important to point out that in this paper we focus on the case where the central rationale for RJVs is the avoidance of duplication in R\&D. This is captured by the assumption that the nature of research discoveries made by firms is duplicative. We fully recognize that an important alternative motivation of RJVs is to exploit complementarities, and in Katsoulacos and Ulph (1998a) we provide a positive analysis of this case. However, a full welfare analysis of this case would require a separate paper.

\subsection{Preliminaries}

In thinking about the interaction between environmental policy and the performance of environmental RJVs, it is important to recognize that there are a number of market failures in operation. One type of failure is product market failures. Taking as given the number of firms, the products they produce, and the technology ${ }^{7}$ they employ, there are two market failures that can arise in relation to firms' output decisions. The first is the conventional pollution externality, which typically leads firms to overproduce. The second is imperfect competition arising from the oligopolistic nature of markets. This, in turn, may be attributable to entry barriers - in particular the scale economies generated by R\&D. Imperfect competition typically leads to firms producing too little output. It is well known that in principle an emissions tax can be chosen to obtain the first-best level of output. Notice that the tax that achieves this first-best will depend on the technologies employed by the firms.

Another type of failure is innovation market failure. To facilitate discussion, here and throughout the rest of the paper we assume that (1) there are only two firms; (2) the products that firms produce are perfect substitutes; and (3) the research paths that firms are pursuing are perfect substitutes (or, more accurately, perfect duplicates) in the sense that if both firms make a discovery, they have discovered exactly the same thing and so can-

7. In particular, emissions technology. 
not gain from any knowledge sharing. The first two assumptions are made in most of the RJV literature, but are by no means innocuous. The third captures one of the possible reasons why an RJV forms - to avoid duplication. However, it ignores another potential gain from RJV formationexploiting research complementarities. We fully recognize the importance of this motive, and have recognized it in the positive analysis contained in Katsoulacos and Ulph (1998a). However, a full treatment of this case in the context of the welfare analysis we conduct here would warrant another paper.

It is well known in the industrial organization literature that there are significant market failures in the innovation process. These stem primarily from the public-good nature of knowledge, as something that is costly to produce, but virtually costless to reproduce. As is well known, this implies that the optimum allocation of resources involves having R\&D undertaken in a relatively small number of labs, with the results being sold to others at a price equal to the value that society places on this knowledge. In this idealized market system, firms undertaking any $R \& D$ would perceive a return equal to the value that the entire industry places on it.

However, in the absence of any policy intervention, actual market mechanisms will not produce such an outcome. In particular, free riding on discoveries would so lower the rate of return to $R \& D$ that very little $R \& D$ would be undertaken. In the face of this market failure, virtually all governments institute a system of protection of intellectual property rights, of which the patent system is the major part.

While patents provide some correction of the fundamental market failures, they involve their own distortions, essentially because they reward firms for discovering information, but not for sharing it. To see what market failures still exist under a patent system, suppose for the moment that patents are fully effective (i.e., there are no involuntary information leakages) and that there are no mechanisms for sharing information.

To fully understand the nature of market failures, it is useful to follow Ulph and Katsoulacos (1998) and distinguish three stages in innovation decisions: (1) research design, in the case considered here, amounts to choosing the number of labs to operate; (2) $R \& D$ involves choosing the amount of R\&D to do in each lab; and (3) information sharing entails choosing the amount of information to share with the other lab if a lab makes a discovery.

We then know that when firms act noncooperatively their decisions are subject to the following potential market failures. ${ }^{8}$ Working backward: At the information sharing stage, firms will fail to share information when it is always socially desirable to do so. At the R\&D stage there are three

8. The discussion that follows is based heavily on the analysis in Ulph and Katsoulacos (1998). 
market failures: (1) the undervaluation effect, in which firms base decisions on profits rather than total surplus (profits plus consumer surplus), and so do too little R\&D; (2) the self-centeredness effect, in which firms base decisions on the gains to themselves from having a new technology rather than the gain to the industry if everyone had the new technology, again resulting in too little R\&D; and (3) the "competition to be first" effect, in which firms have incentives to try to be the first to introduce a new technology, leading to their overinvesting in $\mathrm{R} \& \mathrm{D}$. At the research design stage, there may be excessive duplication because each firm will operate its own lab when it may be socially optimal to operate a single lab.

Suppose now that patents are not completely effective, and there are involuntary unpaid information leakages - spillovers. This will mitigate some of the welfare losses at the information sharing stage, but will introduce a fourth distortion at the R\&D stage because firms acting independently will not internalize the externality arising from the spillover. We call this the spillover effect. It introduces a third reason why firms will underinvest in R\&D.

Notice that it is not at all clear whether, on balance, firms are doing too little or too much R\&D, either individually or collectively. What is clear is that a major reason why these market failures arise is that, by themselves, patents do not reward firms for sharing information. To resolve these difficulties, it is therefore necessary to introduce mechanisms that reward firms for sharing information. Two widely discussed methods of doing this are through licensing and through the creation of RJVs.

While licensing is certainly used in certain contexts, it is not a general solution to all these problems. In the first place, while it will often solve the information sharing problem that arises in the final stage of the decision-making process, it will not always do so. This is because even when there are only two firms - a buyer and a seller - a license will only be sold if the maximum amount the buyer is willing to pay exceeds the minimum amount the seller needs to receive, and this need not always be the case. More seriously, licensing will not solve the problems arising in the first two stages of innovation decision making. In particular, it does not eradicate the competition-to-be-first effect because, instead of competing to be the first to get exclusive use of a new technology, firms compete to be the first to be able to license it.

Given these problems with licensing, attention has focused recently on RJVs as a possible solution to these market failures. RJVs are arrangements under which firms are allowed to act cooperatively during all three stages of the innovation decision-making process, but are required to compete in the product market. Prima facie it would seem that, by making cooperative decisions about all aspects of innovation, RJVs could mitigate most of the market failures discussed here. By acting cooperatively, firms may be induced to share information and so mitigate the market failure at 
the information sharing stage. Second, acting cooperatively to maximize joint profits firms would internalize any spillovers, eliminate the competition-to-be-first effect, and remove the self-centeredness effect at the R\&D stage. Finally, cooperative decision making means that firms may choose to operate a single lab rather than two independent labs, at the research design stage. These informal arguments suggest that the only market failure that RJVs may not potentially overcome is the undervaluation effect.

Given these potential benefits, it is not surprising that RJVs have received considerable attention. However, when one examines the theoretical literature on the subject, it turns out that, while it has provided some useful insights, nevertheless there are a number of weaknesses in the way it typically models RJVs and consequently the analysis fails to fully address many of these failure issues. ${ }^{9}$ The major weaknesses of this literature are as follows.

First, spillovers are treated as exogenous. Either spillovers are the same in the cooperative equilibrium and the noncooperative equilibrium or else it is assumed that they are greater in the cooperative equilibrium. In neither case does the theory explain how cooperation might lead to greater information sharing.

Second, research discoveries by firms are assumed to be perfect complements. In both the cooperative and the noncooperative equilibria, it is assumed that information gained from other firms just adds to the progress that a firm makes on its own. This ignores the possibility of needless duplication of research and also that one of the benefits of an RJV is that it increases the degree of complementarity.

Third, a related problem is that equilibria are assumed to be symmetrical. In particular, in both the cooperative and the noncooperative equilibria, all firms are active in $R \& D$ and all do the same amount of R\&D. This ignores the possible cost savings by concentrating $\mathrm{R} \& \mathrm{D}$ in a smaller number of labs.

Fourth, the noncooperative equilibrium is taken to be one in which no licensing is possible. Since many of the models assume that there are just two firms, it would seem sensible to allow the possibility of licensing, particularly if one wants to understand the full benefits of cooperation versus noncooperation.

To get a sense of just how limiting these assumptions are, it is worth noting the following result by Hinloopen (1997).

Result 1. Suppose we have an industry comprising $n$ identical firms. In addition, suppose $R \& D$ spillovers are the same in both the cooperative and

9. Of course, not every paper suffers from every one of the weaknesses we identify. However, most of them arise in the paper by d'Aspremont and Jacquemin (1988), which has become a classic reference in the literature. 
the noncooperative equilibria, the only policy instrument available to the government is an $R \& D$ subsidy, $R \& D$ discoveries are perfect complements in both the cooperative and noncooperative equilibria, both the cooperative and the noncooperative equilibria are symmetrical; and the $R \& D$ subsidy can be financed by nondistortionary taxation. Then the cooperative and noncooperative $R \& D$ equilibria achieve exactly the same level of welfare.

Proof. The proof is simple. Given the assumptions, effectively the only variable that can be chosen by both firms and the social planner is the amount of R\&D per firm. Work out the second-best ${ }^{10}$ optimum level of R\&D. R\&D per firm will be monotonically increasing in the level of subsidy in both the cooperative and the noncooperative equilibria. So, whether firms act cooperatively or noncooperatively the subsidy can always be chosen to make these equilibria coincide with the second-best optimum.

The conclusion, then, is that as long as governments can subsidize R\&D (which typically they do), then the promotion of RJVs is irrelevant. But this just emphasizes the point that the underlying model fails to capture virtually all of the factors that make RJVs interesting in the first place.

There is an immediate corollary.

COROLlary 1. Suppose now that there are environmental externalities; that firms undertake environmental $R \& D$ that lowers emissions per unit of output; and that, in addition to the $R \& D$ subsidy, the government can also impose an emissions tax. Suppose also that all the other assumptions of result 1 hold. Then, once again, the cooperative and noncooperative equilibria achieve exactly the same level of welfare.

Proof. The fact that the government has an emissions tax means that it can now control output and so can now achieve the first-best level. So choose output per firm and R\&D per firm so as to achieve the first-best. Then, whether firms act cooperatively or noncooperatively, choose the tax rate and $\mathrm{R} \& \mathrm{D}$ subsidy per firm so as to achieve the first-best.

This corollary allows us to immediately generalize from the case of the noncooperative equilibrium analyzed in Katsoulacos and Xepapadeas (1996) to that of a cooperative equilibrium. This shows that in order to have an interesting theory of the interaction between environmental policies and RJV performance, one needs a more interesting model of R\&D one that gives scope for RJVs to achieve some of the objectives they are supposed to achieve. Recent papers by Katsoulacos and Ulph (1998a, 1998b) have gone some way toward correcting the weaknesses of the ex-

10. If governments have no output instrument, then we are confined to second-best optima. 
isting RJV literature and so providing a better account of how RJVs perform. Their models have the following features.

1. Information sharing is endogenous in both the cooperative and noncooperative equilibria. In particular, the possibility of licensing is allowed in the noncooperative equilibrium.

2. They allow for the possibility of both complementarity and substitutability between research discoveries.

3. They determine the number of research labs that will be active in the cooperative equilibrium. ${ }^{11}$

For the case where there are just two firms, they obtain the following results. ${ }^{12}$ First, firms may not share information within an RJV. When RJVs withhold information they do so for anticompetitive reasons. For example, this will happen whenever industry profits are higher and one firm has lower costs than the other and can exploit this to exercise some degree of monopoly power. However, the conditions under which information is shared in an RJV are exactly the same as those under which it is licensed in a noncooperative equilibrium. Hence, in this two-firm setting, RJVs perform no better or worse than the noncooperative equilibrium at the information sharing stage of innovation decisions. Second, RJVs may close a lab, but may do so for two reasons: to eliminate needless duplication and to avoid competition that arises when both firms discover the new technology. Third, while RJVs may give rise to a higher level of welfare than in the noncooperative equilibrium, there is a range of circumstances under which they do not.

In this paper we wish to explore the interaction between environmental policy and the performance of environmental RJVs within the framework for analyzing RJV performance proposed by Ulph and Katsoulacos (1998). To understand some of the issues involved in undertaking this exercise, we briefly set out the main features of a very simple version of the Ulph and Katsoulacos (1998) model adapted to the case of environmental innovation.

There are two firms producing a homogeneous product. Initially both firms use a technology whereby emissions per unit of output are $\bar{e}>0$. Firms undertake R\&D in order to discover a new technology for which emissions per unit of output are $\underline{e}, 0<\underline{e}<\bar{e}$. Each firm's probability of

11. Each firm operates its own lab in the noncooperative equilibrium.

12. While these papers do not allow for the possibility of an R\&D subsidy, it is clear that in this framework such a subsidy will not, in general, enable governments to achieve a second-best outcome under either cooperation or noncooperation. This is particularly true when the social optimum involves closing a lab. An R\&D subsidy may encourage an RJV to keep a lab open that it would otherwise have closed. Thus, the Hinloopen result will not generalize to this case. 
discovery depends solely on the R\&D that it does, and these probabilities are independent. There are three possible outcomes of the R\&D process: (1) neither firm discovers the new technology; (2) both firms discover the new technology, but, since they have discovered the same thing, there is nothing to be gained from sharing the information; ${ }^{13}$ and one firm alone discovers the new technology, in which case a decision has to be made whether to reveal the new technology to the firm that has not discovered it.

Assume for the moment that the only policy instruments open to the government are an emissions tax and the decision whether to allow firms to form RJVs. As in all the literature on RJVs, we assume that if firms are allowed to cooperate on decisions relating to innovation, they are forced to compete in the output market.

In modeling the impact of the emissions tax on the performance of RJVs, an important issue arises as to when in the decision-making process this decision is made. Notice that, leaving aside the tax-setting decision, the decisions made by firms and the government constitute a six-stage game.

1. RJV policy: The government decides whether or not to allow RJVs.

2. RJV formation: If RJVs are allowed, firms choose whether or not to form one.

3. Research design: Firms choose the number of labs to operate.

4. $R \& D$ : Firms choose the amount of $\mathrm{R} \& \mathrm{D}$ to do in each lab.

5. Information sharing: Depending on the outcome of the R\&D decisions, firms choose whether or not to share information.

6. Output: Firms choose output in a noncooperative Cournot equilibrium.

To understand the impact of the environmental policy instrument (emissions tax), notice that there are many different assumptions one can make about when this instrument gets chosen and the information available to the government when the decision is made. This timing issue reflects the ability of the government to commit itself to the decision. To illustrate this point, consider two possible assumptions that we could make.

Assumption 1: Government Is Unable to Commit. Here the government sets the tax rate at the start of stage 6 , after it has learned what technology each of the two firms is operating, but before firms have chosen output. The tax will be set to maximize welfare, conditional on the technologies employed by the two firms. This setup corresponds to the conventional

13. This reflects the assumption mentioned before that research discoveries are perfect substitutes. This is the opposite end of the continuum from most of the literature on RJVs, which focuses on the case of complementary research discoveries. 
static analysis of environmental policy with given technologies. Notice that effectively the government sets three tax rates, $t^{11}, t^{10}$, and $t^{00}$, depending on whether both firms have the new technology, only one firm has the new technology, or neither firm has the new technology, respectively. The tax rate chosen by the government in each of these three states will involve balancing the two product-market failures already discussed. Thus, the government wants high taxes to discourage emissions, but low taxes to promote competition. Notice that since all the R\&D and information-sharing decisions have already been made, the taxes chosen at this stage will be exactly the same whether or not firms have cooperated. So the taxes are conditioned only on technology, not on the previously made decision about whether or not to cooperate. Let $\hat{t}^{11}, \hat{t}^{10}$, and $\hat{t}^{00}$ be the optimum taxes set under this assumption.

Assumption 2: Government Has Some Ability to Commit. Here we could think of the tax being set at the start of stage 5, after firms have chosen $\mathrm{R} \& \mathrm{D}$ and after the outcome of the $\mathrm{R} \& \mathrm{D}$ race is known, but before the information-sharing decision is made. Notice that what the government announces are the taxes that it will set in stage 6 conditional on the technologies that each firm will have at that stage (i.e., conditional on the information-sharing decision that is about to be made at stage 5). Now there are three possible situations the government can be in at the start of stage 5: (1) If both firms have discovered the new technology, the only possible state that can arise at the start of stage 6 is state 11 , and since there is no information-sharing decision to be made, it will simply announce $\hat{t}^{11}$. (2) If neither firm has discovered the new technology, by analogous reasoning the government will announce $\hat{t}^{00}$. (3) If one firm has discovered the new technology and the other firm has not, the economy will be in either state 11 or state 10 at the start of stage 6 , but now the choice of tax rates in these two states can influence the information-sharing decision and obviously the optimal thing for the government to do is to announce a tax $\tilde{t}^{10}$ that is so high that the firms will choose to fully share information. Thus, by being able to fully commit itself at the information sharing stage in the process, the government can induce the first-best level of information sharing in both the cooperative and noncooperative equilibria.

We could think of taxes being set at yet earlier stages in the decisionmaking process, and, in general, the taxes that are set will depend on the precise stage at which the decision is made. Rather than conduct an exhaustive analysis of all possible situations, we will confine our attention to the case where the government is unable to commit and explore the implications of this assumption for the desirability of permitting RJVs. We will contrast our conclusions with those obtained by Ulph and Katsoulacos (1998) for the case of nonenvironmental R\&D. 
Before proceeding to the detailed model, note the following two points. First, once we take account of the decision about environmental tax rates, we now effectively have the following seven-stage game:

1. RJV policy: The government decides whether or not to allow RJVs.

2. RJV formation: If RJVs are allowed, firms choose whether or not to form one.

3. Research design: Firms choose the number of labs to operate.

4. $R \& D$ : Firms choose the amount of $\mathrm{R} \& \mathrm{D}$ to do in each lab.

5. Information sharing: Depending on the outcome of the R\&D decisions, firms choose whether or not to share information.

6. Emissions tax: The government sets environmental taxes $t^{11}, t^{10}$, or $t^{00}$, conditioning on the technology that each firm has as a result of the outcomes of stages 4 and 5 .

7. Output: Firms choose output in a noncooperative Cournot equilibrium.

Second, given the stage at which they are set, the environmental taxes chosen by the government will be exactly the same irrespective of whether firms have made their decisions at stages 3, 4, and 5 in a cooperative or noncooperative fashion. It therefore follows that, if they are allowed to do so, firms will indeed choose to form an RJV at stage 2.

In section 10.2 we explore what decision the government should make at stage 1. From the discussion thus far it follows that this just reduces to the question of whether expected social welfare is greater if the decisions made at stages 3, 4, and 5 are made cooperatively or noncooperatively. It is important to appreciate that the issues arising in this comparison of the cooperative and noncooperative equilibria are exactly the same as in Ulph and Katsoulacos (1998). The crucial point is that the decisions made at stages 6 and 7 are very different, and the question is therefore how these differences affect our assessment of the balance of factors at stages 3, 4, and 5. There are three key differences: (1) The government has an instrument that can influence output decisions. (2) The presence of environmental damage means that there are two wedges between the profits that firms use to guide their decisions and the social welfare calculations that the government will use (consumer surplus and environmental damage). This will influence the magnitude of the undervaluation effect. (3) Since the tax rate will depend on decisions about information sharing, the relationship between profits and surplus will vary across states in a complex way. Taken together, these three factors will affect whether the cooperative or the noncooperative equilibrium comes closer to achieving the socially optimal innovation decisions. 


\subsection{The Model}

Consider a closed economy in which there are just two goods: a "dirty" good whose production causes emissions of some pollutant and expenditure on all other goods. Let $X$ denote aggregate consumption and production of the dirty good and $Z$ the aggregate expenditure on all other goods.

There is a single consumer with utility function

$$
u(X, Z) \equiv a X-\frac{1}{2} \cdot X^{2}+Z .
$$

There are two firms producing $X$. Denote the output of firm $i$ by $x_{i}>0$, $i=1,2$, so $X=x_{1}+x_{2}$. There is a perfectly competitive sector producing $Z$ under constant returns to scale. $Z$ is numeraire.

There are two possible technologies for producing $X$ : an old (i.e., existing) technology and a new one that has yet to be discovered. For each technology, unit costs of production are $c, 0<c<a$. Emissions per unit of output with the new technology are $\underline{e}=1$, and with the old technology $\bar{e}=1+\theta, 0<\theta<1$. Thus technologies differ only in their environmental attributes; that is, we are dealing with purely environmental innovation. The parameter $\theta$ provides a measure of how much better the new technology is compared to the old one in terms of its emissions properties.

If firm $i$ produces output $x_{i}$ using a technology that generates emissions per unit of output $e_{i} \in\{1,1+\theta\}$, then the total emissions, $E$, produced by the two firms are $E=x_{1} \cdot e_{1}+x_{2} \cdot e_{2}$. We assume that the damage done by these emissions is given by the function $D(E)=(d / 2) \cdot E^{2}$.

In order to discover the new technology with lower emissions levels, firms undertake R\&D. If the two firms act noncooperatively, they each operate their own independent lab. If they form an RJV, then at stage 3 they can choose either to continue to operate one lab each or to operate a single combined lab.

In stage 4 , firms choose the amount of $R \& D$ to do in each lab. The amount of $\mathrm{R} \& \mathrm{D}$ a lab does determines the probability that it will discover the new technology. If both firms undertake $R \& D$, then each has an independent probability of discovery that depends solely on the amount of R\&D that it itself undertakes. Thus, as in Katsoulacos and Ulph (1998a), there are no R\&D input spillovers, only $R \& D$ output spillovers.

As in Ulph and Katsoulacos (1998), we assume that the R\&D expenditure that a lab needs to undertake in order to get a probability of discovery $p, 0 \leq p \leq 1$, is

$$
\gamma(p) \equiv \frac{1}{1-\beta}\left[1-(1-p)^{1-\beta}\right]-p, \quad 0<\beta<1 .{ }^{14}
$$

14. It is worth noting that as $\beta \rightarrow 1, \gamma(p) \rightarrow-\log (1-p)-p$. 
Thus,

$$
\begin{gathered}
\gamma(0)=\gamma^{\prime}(0)=0 ; \quad \gamma^{\prime \prime}(0)=\beta>0 ; \\
\forall p, 0<p<1 \quad \gamma(p)>0 ; \quad \gamma^{\prime}(p)=(1-p)^{-\beta}-1>0 ; \\
\gamma^{\prime \prime}(p)=\beta(1-p)^{-\beta-1}>0 ; \\
\text { as } p \rightarrow 1, \quad \gamma(p) \rightarrow \frac{\beta}{1-\beta^{\prime}}, \quad \gamma^{\prime}(p) \rightarrow \infty .
\end{gathered}
$$

The parameter $\beta$ reflects the extent of decreasing returns to $R \& D$ in each lab. As discussed in Ulph and Katsoulacos (1998), this is an important determinant of whether RJVs will choose to operate one or two labs.

In stage 5, decisions are made about sharing the information resulting from the discoveries made in stage 4 . There are three possible outcomes of stage 4. First, neither firm discovers the new technology. Since no information has been discovered, there is no information to be shared, and so both firms continue to operate with a technology in which emissions per unit of output are $\bar{e}=1+\theta$. Second, both firms discover the new technology. We assume that in this case, while each firm has obtained some information, it is exactly the same information, and so there is absolutely nothing to be gained by sharing it. ${ }^{15}$ The reason for making this assumption is that, as we see later, it introduces the possibility of needless duplication of research effort - one of the market failures that RJVs are supposed to alleviate. Thus, in this case each firm now operates with a technology in which emissions per unit of output are $\underline{e}=1$. Third, one firm alone discovers the new technology. The firm that has discovered the new technology will now have emissions per unit of output of $\underline{e}=1$. Now there is some information to be shared, and something to be gained (at least by the recipient) from sharing it. We assume that there are just two possible decisions to be made about information sharing: ${ }^{16}$ either no information is shared, in which case the emissions per unit of output of the firm that has not discovered the technology will be $\bar{e}=1+\theta,{ }^{17}$ or full information sharing takes place, in which case the emissions per unit of output of the firm that has not discovered the technology will be $\underline{e}=1 .^{18}$

Notice now that if one firm alone discovers the new technology, and if

15. In the terminology used by Katsoulacos and Ulph (1998a), the research discoveries are perfect substitutes.

16. We show in Katsoulacos and Ulph (1998a) that there is no loss of generality in reducing the options to just two.

17. This ignores the possibility that there may be some involuntary information leakage whereby the emissions of the firm that has not discovered the technology are $1+\theta \cdot \underline{\delta}, 0<$ $\underline{\delta}<1$.

18. This ignores the possibility that the firm that has not discovered the technology may have limited capacity to use the information it receives, so its costs of production are $1+$ $\theta \cdot \bar{\delta}, 0<\bar{\delta}<1$. 
it fully shares the information with the other firm, then the outcome will be precisely the same as if both firms had discovered the technologyeach firm will have emissions $\underline{e}=1$. Thus there is nothing to be gained by having both firms discover the new technology that could not be gained by having just one firm discover the new technology and sharing the results. In this sense, there has clearly been a duplication of research effort.

In stage 6 , the government sets the environmental tax rate. There are three possible situations that can occur at the start of stage 6 , depending on which technology each firm has. First, neither firm has the new technology. This situation can arise only if neither firm discovers the new technology. Variables relating to this situation are described by a superscript 00 . Second, both firms have the new technology. This situation can arise if either both firms discover the new technology or if only one does and information is fully shared. Variables relating to this situation are described by the superscript 11 . Third, only one firm has the new technology. This situation can arise only if just one firm discovers the new situation and information is not shared. Aggregate variables relating to this situation are described by the superscript 10 . Variables relating to individual firms will carry the superscript 10 for the firm that has the new technology and 01 for the firm that does not. Thus the government effectively sets three tax rates: $t^{11}, t^{10}$, and $t^{00}$.

Finally, in stage 7 output decisions are made conditional on the marginal costs that each firm will have as a result of the decisions made in the previous three stages. We assume that collusion over output is forbidden. Consequently, the output of the two firms is determined as a noncooperative equilibrium. In this paper, we confine attention to the noncooperative Cournot equilibrium. However, the nature of this equilibrium depends on the taxes set by the government in stage 6 .

\subsection{The Solution and the Welfare Measures}

As is conventional we solve the model backward.

\subsubsection{Stage 7: The Cournot Equilibrium}

If firm $i$ has technology $e_{i} \in\{1,1+\theta\}$, and if the government has imposed an emissions tax $t$ per unit of emissions, then, in an interior Cournot equilibrium, the output of firm $i$ is

$$
x_{i}=\frac{(a-c)+t\left(e_{j}-2 e_{i}\right)}{3}, \quad i=1,2 ; j \neq i,
$$

and the profits it makes are

$$
\pi_{i}=\left(x_{i}\right)^{2} .
$$




\subsubsection{Stage 6: The Tax-Setting Decision}

Since all the innovation decisions have already been made, all the government can influence at this stage is the output equilibrium in stage 7 . All that matters to the government, then, is the flow of welfare, comprising consumer surplus, producer surplus (profits), and environmental damage.

If firm $i$ produces output $x_{i}$ using a technology that generates emissions per unit of output $e_{i} \in\{1,1+\theta\}$, then the total emissions, $E$, produced by the two firms are $E=x_{1} \cdot e_{1}+x_{2} \cdot e_{2}$. As noted before, we assume that the damage done by these emissions is given by the function $D(E)=(d / 2)$ - $E^{2}$. The flow of social welfare in this output market situation is, therefore,

$$
\begin{aligned}
W\left(x_{1}, x_{2} ; e_{1}, e_{2}\right) \equiv & (a-c)\left(x_{1}+x_{2}\right)-\frac{1}{2}\left(x_{1}+x_{2}\right)^{2} \\
& -\frac{d}{2}\left(x_{1} \cdot e_{1}+x_{2} \cdot e_{2}\right)^{2} .
\end{aligned}
$$

By substituting the equilibrium outputs in equation (1) into the social welfare function (2), we can determine social welfare as a function of the tax rate alone. Consequently, we can determine the optimum tax rate and the equilibrium to which it gives rise.

To understand this more fully, it is useful to consider in turn two separate cases. In case 1, both firms have the same emissions per unit of output, $e \in\{1,1+\theta\}$. Notice that in this case both firms will choose identical output, and so it follows from equation (1) that welfare depends solely on the aggregate level of output, $X$. Thus we can write

$$
W=(a-c) X-\frac{1+d \cdot e^{2}}{2} \cdot X^{2} .
$$

From equation (2) we know that equilibrium aggregate output is

$$
X=\frac{2}{3} \cdot(a-c-t \cdot e),
$$

so it now follows that, by suitable choice of $t$, the government can achieve the first-best level of welfare.

From equation (3) it follows that the first-best level of aggregate output is

$$
\hat{X}=\frac{a-c}{1+d \cdot e^{2}} .
$$

Combining equations (3) and (4), we see that the tax rate that achieves the optimum is 


$$
\hat{t}=\frac{(a-c) \cdot\left(2 d \cdot e^{2}-1\right)}{2 \cdot e \cdot\left(1+d \cdot e^{2}\right)} .
$$

It is straightforward to check that welfare in the social optimum is

$$
\hat{W}(e)=\frac{1}{2} \cdot \frac{(a-c)^{2}}{1+d \cdot e^{2}},
$$

and industry profits in the social optimum are

$$
\Sigma(e)=\frac{1}{2} \cdot\left(\frac{a-c}{1+d \cdot e^{2}}\right)^{2}
$$

Thus,

$$
\Sigma(e)=\frac{\hat{W}(e)}{1+d \cdot e^{2}} .
$$

This shows that industry profits understate social welfare and that the gap is larger when both firms have the old technology than when they both have the new technology.

To ease notation later on, let $t^{11}, W^{11}, \Sigma^{11}\left(t^{00}, W^{00}, \Sigma^{00}\right)$ denote the optimal tax rate and the flow levels of welfare and industry profits when both firms have the new (old) technology. We have

$$
\begin{gathered}
t^{11}=\frac{(a-c) \cdot(2 d-1)}{2(1+d)}, \quad W^{11}=\frac{(a-c)^{2}}{2(1+d)}, \quad \Sigma^{11}=\frac{1}{2} \cdot\left(\frac{a-c}{1+d}\right)^{2}, \\
t^{00}=\frac{(a-c) \cdot\left[2 d \cdot(1+\theta)^{2}-1\right]}{2 \cdot(1+\theta) \cdot\left[1+d \cdot(1+\theta)^{2}\right]}, \quad W^{00}=\frac{(a-c)^{2}}{2 \cdot\left[1+d \cdot(1+\theta)^{2}\right]}, \\
\Sigma^{00}=\frac{1}{2} \cdot\left(\frac{a-c}{1+d \cdot(1+\theta)^{2}}\right)^{2} .
\end{gathered}
$$

In case 2, firm 1 has the old technology and firm 2 the new technology. This case can only arise if one firm has discovered the new technology, but does not share the information. Notice first of all that, in general, the government can now no longer obtain the first-best output equilibrium. Since the two firms have different technologies, they will choose different output levels. The first-best level would require getting both of these output levels right, and with just a single instrument - the environmental tax rate - this typically is impossible to achieve. In particular, the first-best level would require that only firm 2 be active and so act as a monopolist. For this possibility to arise it would have to be the case that when the government sets the tax that would be optimal if firm 2 were a monopolist, then firm 1's costs would be so high that it would not be willing to enter. 
It is straightforward to confirm that this can only arise if $\theta \geq d /(d-1)>$ 1. Since in this paper we assume that $\theta \leq 1$, we can rule this possibility out. Indeed, throughout the paper we wish to confine our attention to the case where, in the optimum, both firms are active. To analyze this situation, we will begin by assuming that both firms are active, derive the optimum tax rate under this assumption, and then check that, given this tax rate, both firms are indeed active.

In an interior Cournot equilibrium, the individual and aggregate outputs of the two firms are as follows:

$$
\begin{aligned}
& x_{1}=\frac{a-c-t(1+2 \theta)}{3}, \\
& x_{2}=\frac{a-c-t(1-\theta)}{3},
\end{aligned}
$$

and

$$
X=\frac{2(a-c)-t(2+\theta)}{3} .
$$

Total emissions are

$$
E=X+\theta \cdot x_{1}=\frac{(a-c) \cdot(2+\theta)-2 t \cdot\left(1+\theta+\theta^{2}\right)}{3} .
$$

Social welfare is $W=(a-c) \cdot X-1 / 2 \cdot X^{2}-(d / 2) \cdot E^{2}$, and so the optimal tax arises where

$$
W^{\prime}=[(a-c)-X] \cdot X^{\prime}-d \cdot E \cdot E^{\prime}=0 .
$$

Carrying out the calculation, we find that

$$
t^{10}(\theta, d)=\frac{(a-c) \cdot(2+\theta) \cdot\left[2 d\left(1+\theta+\theta^{2}\right)-1\right]}{d \cdot\left[2\left(1+\theta+\theta^{2}\right)\right]^{2}+(2+\theta)^{2}} .
$$

Before discussing the properties of the optimum tax, we need to confirm that this tax rate is consistent with our assumption of an interior Cournot equilibrium (with a positive output for firm 1). It is easy to see that this condition requires that

$$
t^{10}(\theta, d)<\frac{(a-c)}{1+2 \cdot \theta}
$$

We note below that $t^{10}$ is a strictly increasing function of $d$, so this condition requires that

$$
d<\bar{d}(\theta) \equiv \frac{2+3 \theta+\theta^{2}}{2 \cdot \theta \cdot\left(1+\theta+\theta^{2}\right)}
$$


Table 10.1 Computed Values of $d$

\begin{tabular}{ll}
\hline$\theta$ & $\bar{d}(\theta)$ \\
\hline 0.1 & 10.405 \\
0.3 & 3.585 \\
0.5 & 2.142 \\
0.7 & 1.497 \\
1 & 1 \\
\hline
\end{tabular}

It is straightforward to check that $\bar{d}(\theta)$ is strictly decreasing in $\theta$. For later purposes, table 10.1 shows the values taken by this function for a range of values of $0<\theta \leq 1$. We can also invert $\bar{d}(\theta)$ to obtain the function $\bar{\theta}(d)$, which gives, for any $d$, an upper bound on $\theta$ for which the optimal tax yields an interior Cournot equilibrium.

What are the properties of the optimal tax when firms do not share information? As noted previously, it is easy to check that $t^{10}$ is a strictly increasing function of $d$. Thus, as we would expect, the more damaging are emissions, the higher is the optimal tax. The crucial question is how $t^{10}$ varies with $\theta$ because later on we will want to know whether the tax rate is higher if firms do not share information than if they do share information. That is, we will want to know whether $t^{10}(\theta, d) \lesseqgtr t^{11}$. Now it follows by definition and from formula (5) that

$$
t^{10}(0, d)=\frac{(a-c)(2 d-1)}{2(d+1)}=t^{11},
$$

so what we really want to know is whether $t^{10}(\theta, d) \lesseqgtr t^{10}(0, d)$.

To answer this question consider first two extreme cases. In one case, when $d=0$,

$$
t^{10}(\theta, 0)=-\frac{a-c}{2+\theta}<0, \quad \frac{\partial t^{10}}{\partial \theta}=\frac{a-c}{(2+\theta)^{2}}>0 .
$$

Thus, as we would expect, when there is no environmental damage the government imposes a subsidy to correct the loss arising from imperfect competition. However, because the subsidy is imposed on emissions rather than on output, the subsidy itself induces what is in this case an unwarranted asymmetry between the two firms. A larger value of $\theta$ means the subsidy has to be smaller (i.e., the negative tax larger) in order to reduce the unwarranted distortion.

In the second case, when $d \rightarrow \infty$,

$$
t^{10}(\theta, \infty)=\frac{(a-c) \cdot(2+\theta)}{2\left(1+\theta+\theta^{2}\right)}>0, \quad \frac{\partial t^{10}}{\partial \theta}=-\frac{(a-c) \cdot\left(1+4 \theta+\theta^{2}\right)}{2\left(1+\theta+\theta^{2}\right)^{2}}<0 .
$$


Accordingly for the five values of $d$ shown in the right-hand column of table 10.1 , we have calculated the value of $t^{10}$ as $\theta$ ranges over values in the interval $0 \leq \theta \leq \bar{\theta}(d)$. The results are presented in appendix tables 10A.1-10A.5. These show that when $d$ is small the optimal tax first rises and then falls with $\theta$, while when $d$ is large the optimal tax is a strictly decreasing function of $\theta$.

The intuition behind these results is as follows. In setting the tax, the government is trying to correct two distortions: (1) that caused by imperfect competition and (2) that caused by pollution. Consider these in turn. For the first distortion, the larger $\theta$ is, the lower is aggregate output, and so the greater the loss arising from imperfect competition. This suggests that the optimal tax should fall with $\theta$. For the second distortion, when $d$ is small, so too is the optimal tax, and, when $\theta \approx 0$, an increase in $\theta$ causes aggregate emissions to rise-which calls for an increase in the optimal tax to correct this distortion. On balance, the second factor outweighs the first when $\theta \approx 0$ causes the optimal tax to rise with $\theta$. However, when $d$ is large, so too is the optimal tax, and it is easy to check that in this case aggregate emissions are a strictly decreasing function of $\theta$, so this second factor also calls for the optimal tax to fall with $\theta$.

Having determined the optimal tax, we can substitute this back into the expressions for output, profits, and welfare, and so determine aggregate profits, $\Sigma^{10}$, and aggregate welfare, $W^{10}$ as functions of the underlying parameters $d$ and $\theta$. These profit and welfare expressions can then be used to determine the equilibrium and optimum information-sharing and R\&D decisions in stages 2 and 1, respectively. To these we now turn.

\subsubsection{Stage 5: The Information-Sharing Decision}

Suppose that just one firm has discovered the new technology. If it does not share information, then the resulting levels of aggregate welfare and aggregate profits will be $W^{10}$ and $\Sigma^{10}$, respectively. If information is shared, then the resulting levels of aggregate welfare and aggregate profits will be $W^{11}$ and $\Sigma^{11}$, respectively.

As discussed in Ulph and Katsoulacos (1998), information sharing will be socially desirable if and only if $W^{11}>W^{10}$, and will be privately profitable in both the cooperative and noncooperative equilibria (under licensing) if and only if $\Sigma^{11}>\Sigma^{10}$. Unfortunately, the expressions for aggregate profits, $\Sigma^{10}$, and aggregate welfare, $W^{10}$, that emerge from the analysis in stage 6 are sufficiently complex that it is extremely difficult to explore these inequalities analytically, so we have had to explore them numerically. Appendix tables 10A.1-10A.5 give the computed values for profits and welfare as $\theta$ ranges over values in the interval $0 \leq \theta \leq \bar{\theta}(d)$. In reading these tables, it is important to bear in mind that the first row, corresponding to the case $\theta=0$, corresponds to the situation where both firms have a tech- 
nology with emissions levels of 1 , and so the levels of welfare and profits here are $W^{11}$ and $\Sigma^{11}$, respectively.

An inspection of these appendix tables shows that in all cases welfare is lower when $\theta>0$ than when $\theta=0$; that is, $W^{11}>W^{10}$, and so, as we would expect, full information is socially desirable. This is because, when information is fully shared, both firms have the least-polluting technology, and the government can then use its tax powers to achieve the first-best levels of output.

Let us now consider the private information-sharing decision of the two firms. From Ulph and Katsoulacos (1998), we know that firms will choose not to share information whenever the firm with the new technology has a sufficient cost advantage. This enables it to exercise significant market power, and so the resulting industry profits are higher than would be the case if both firms had the new low-cost technology and the industry was consequently very competitive. The difference now is that the cost difference between firms depends on both the difference in technology, as reflected in the parameter $\theta$, and on the tax rates $t^{11}, t^{10}$.

To understand what is going on here, consider first the case where the government sets some arbitrary tax rate $t$, which is independent of the technologies actually used by the two firms, and thus is the same whether or not information is shared. Then it follows from the result in Ulph and Katsoulacos (1998) that information will definitely be shared if

$$
t(2+5 \theta)<a-c,
$$

and will definitely not be shared if inequality (6) is reversed. This shows that the information-sharing condition depends on both the tax rate, $t$, and on the technology gap parameter, $\theta$, and that information is shared when both $t$ and $\theta$ are small.

As a variant of this thought experiment, suppose now that instead of setting an arbitrary tax rate, the government sets the same tax rate $t^{11}$ whether or not information is shared. Then inequality (6) becomes

$$
\theta<\tilde{\theta}(d) \equiv \frac{6}{5(2 d-1)} .
$$

In the appendix, we present the values of $\tilde{\theta}(d)$ corresponding to each of the values of $d$ in table 10.1 . We see that when $d=1$, then $\tilde{\theta}(1)>\bar{\theta}(1)$, and so, if the government sets the tax rate $t^{11}$, whether or not the information is shared, then, for this value of $d$ information will always be sharedthat is, will be shared for all values of $\theta \in[0, \bar{\theta}(1)]$. However, when $d>1$, $\tilde{\theta}(d)<\bar{\theta}(d)$, and so information will not always be shared-that is, will not be shared for all values of $\theta \in[0, \bar{\theta}(d)]$. In particular, information will only be shared if emissions under the old technology are sufficiently close to those with the new technology. 
An alternative way of seeing what is going on here is to let $\tilde{\lambda}(d) \equiv$ $\min \{[\tilde{\theta}(d)] /[\bar{\theta}(d)], 1\}$ measure the fraction of the range of feasible values of $\theta$ over which information is shared. Then we see from appendix tables 10A.1-10A.5 that $\tilde{\lambda}(1)=1$, but that $\tilde{\lambda}(d)$ is a strictly decreasing function of $d$. In this sense, we conclude that information sharing becomes less likely the larger the value of $d$.

These results are in line with the work of Ulph and Katsoulacos (1998). Information sharing is likely when the cost differences are small. When the damage is small, then so too is the optimal tax rate, and so cost differences are small for all $\theta \in[0, \bar{\theta}(d)]$. However when damage is large, so too is the tax rate, and so information will only be shared when the underlying technology gap parameter $\theta$ is sufficiently small.

Finally, when we recognize that the government will in fact set a different tax rate $t^{10}$ if information is not shared from the tax rate $t^{11}$ that will be set if information is shared, then we need to know whether $\Sigma^{11}>\Sigma^{10}$. From the discussion so far we know that $\Sigma^{11}$ is the value of industry profits when $\theta=0$. So, in looking at the appendix tables, we can determine whether or not information is shared in any given situation by simply comparing the value of industry profits $\Sigma^{10}$ with that given in the first row of appendix tables 10A.1-10A.5.

We see that when $d=1$, for all positive values of $\theta \leq \bar{\theta}(1)$, industry profits are lower than in the case where $\theta=0$ - that is, information is always shared. However, when $d>1$, then, by interpolation, there exists a $\breve{\theta}(d), 0<\breve{\theta}(d)<\bar{\theta}(d)$ such that industry profits are the same when $\theta=$ $\breve{\theta}(d)$ as when $\theta=0$. This implies that information will be shared when $0<$ $\theta<\breve{\theta}(d)$ and will not be shared when $\breve{\theta}(d)<\theta \leq \bar{\theta}(d)$.

By analogy with what we did before we can let $\breve{\lambda}(d) \in \min \{[\breve{\theta}(d)] /$ $[\bar{\theta}(d)], 1\}$ denote the fraction of the range of feasible values of over which information is shared when the government sets different tax rates $t^{11}, t^{10}$. From the appendix tables we see that when $d$ is small, then $\breve{\lambda}(d)>\tilde{\lambda}(d)$; but that when $d$ is large, then $\breve{\lambda}(d)<\tilde{\lambda}(d)$. Thus, when the government sets different taxes if firms share information than if they do not, then, compared to the situation where the same tax rate is set irrespective of the information-sharing decision, information sharing becomes more likely when the damage is small, but less likely when the damage is large. This latter result follows from the result noted before. When damage is small, taxes tend to increase with $\theta$, which ceteris paribus lowers profits when information is not shared and so makes information sharing more attractive than in the case where taxes do not change with $\theta$. However, when damage is large, taxes tend to fall with $\theta$, which ceteris paribus raises profits when information is not shared and so makes information sharing less attractive than in the case where taxes do not change with $\theta$. Having understood the information-sharing decision we can turn finally to the $\mathrm{R} \& \mathrm{D}$ decisions. 


\subsubsection{Stages 3 and 4: The R\&D Decisions}

We have to determine the amount of R\&D done by each of the two labs in each of the two equilibria-cooperative and noncooperative. In particular, in considering the cooperative (RJV) equilibrium we have to allow for the possibility of an asymmetrical solution in which one of the labs does no R\&D.

Before turning to the more detailed analysis, it is important to make three general points about the nature of the R\&D decisions.

1. As noted in Katsoulacos and Ulph (1998a) and in Ulph and Katsoulacos (1998), although, ex ante, the two firms are identical, the R\&D outcomes need not be. In particular, in both the social optimum and in the cooperative equilibrium, it may turn out to be optimal to have only one firm undertake R\&D. Whether or not this is the case turns on a tradeoff between diminishing returns and needless duplication. The greater the extent of diminishing returns (the larger the parameter $\beta$ in the $R \& D$ cost function) the more likely it is that both labs will be kept open.

2. In the noncooperative equilibrium, both firms will undertake R\&D (and the equilibrium will be symmetrical). This means that the noncooperative equilibrium may be prone to a welfare loss of needless duplication.

3. When firms share information in the noncooperative equilibrium, they do so through licensing. We assume that the license fee is determined by negotiation, and that the licenser and the licensee have equal bargaining power. So the license fee is just halfway between the maximum price that the licensee is willing to pay and the minimum price at which the licenser is willing to sell.

The detailed analysis of the R\&D decisions is now very similar to that given in Ulph and Katsoulacos (1998), so in what follows we just briefly summarize the main points of their analysis.

Point 1 makes it difficult to undertake any general analysis of the R\&D decisions in the social optimum and in each of the two equilibria. Most of the analytical conclusions are therefore obtained in the easier case where both firms undertake R\&D. As noted in our earlier papers, there are then two incentives driving the R\&D decisions-competitive threat ${ }^{19}$ and profit incentive. ${ }^{20}$

Whether or not information is shared, the profit incentive is weakest in the cooperative equilibrium and strongest in the social optimum, with the profit incentive in the noncooperative equilibrium lying between the other two. The profit incentive is strongest in the social optimum because welfare

19. For each firm, this is defined as the difference between the payoff (in terms of profits or welfare) if both firms innovate and the payoff if the other firm alone innovates.

20. For each firm, this is defined as the difference between the payoff if the firm alone discovers the technology and the payoff if neither discovers it. 
is greater than profits - essentially because of the wedge caused by environmental damage. The profit incentive is greater in the noncooperative equilibrium than in the cooperative equilibrium, because most of the gains from having a firm innovate go to the firm that innovates.

When information is shared, the competitive threat is zero in both the social optimum and in the cooperative equilibrium, since the aggregate outcome is exactly the same whether one firm or both discover the new technology. However the competitive threat is positive for the noncooperative equilibrium since an individual firm will always lose if it fails to discover technology when the other firm has done so. The only difference that arises when information is not shared is that the competitive threat in the cooperative equilibrium is then negative, since, by definition, industry profits are lower when both firms discover the technology than when only one does so.

The general conclusions are that when both firms undertake R\&D, then compared to the social optimum, the cooperative equilibrium always underinvests; R\&D spending will be higher in the noncooperative equilibrium than in the cooperative equilibrium; and R\&D spending in the noncooperative equilibrium may be higher or lower than in the social optimum. It is therefore far from obvious that RJVs necessarily perform better than the noncooperative equilibrium in terms of getting the levels of R\&D spending right. Where they may potentially prove beneficial is in eliminating the needless duplication of R\&D effort.

\subsubsection{Stage 2: RJV Membership}

As noted previously, this is trivial. Since the tax rates set in stage 6 do not depend on the RJV-membership decision, and since in a given environment firms are always better off cooperating than not cooperating, the firms will always join an RJV if RJVs are allowed.

\subsubsection{Stage 1: RJV Policy}

The government now has to decide whether or not to allow firms to form an RJV. We know that the information-sharing decision in stage 5 will be exactly the same whether firms act cooperatively or noncooperatively. So, let

$$
\tilde{W}^{10} \equiv\left\{\begin{array}{ll}
W^{11} & \text { if } \Sigma^{11}>\Sigma^{10} \\
W^{10} & \text { if } \Sigma^{10}>\Sigma^{11}
\end{array},\right.
$$

denote the level of welfare that will be achieved if, in stage 4 , one lab discovers the new technology and the other does not, allowing for the information sharing decision that will subsequently be made in stage 5 .

Let $p_{i}^{n}, i=1,2$, denote the noncooperative equilibrium probabilities of discovery by each of the two labs as determined in stages 3 and 4 of the 
game, and $p_{i}^{c}, i=1,2$, denote the corresponding probabilities in the cooperative (RJV) equilibrium. Let $\bar{W}^{n}$ and $\bar{W}^{c}$ denote the expected level of social welfare in the noncooperative and cooperative equilibria, respectively. Then the formula,

$$
\begin{aligned}
\bar{W}^{t}= & p_{1}^{t} \cdot p_{2}^{t} \cdot W^{11}+p_{1}^{t} \cdot\left(1-p_{2}^{t}\right) \cdot \tilde{W}^{10}+p_{2}^{t} \cdot\left(1-p_{1}^{t}\right) \cdot \tilde{W}^{10} \\
& +\left(1-p_{1}^{t}\right) \cdot\left(1-p_{2}^{t}\right) \cdot W^{00}-\gamma\left(p_{1}^{t}\right)-\gamma\left(p_{2}^{t}\right),
\end{aligned}
$$

gives the expected level of social welfare in the equilibrium of type $t$.

To complete our analysis of the model, we have undertaken a numerical comparison of both the cooperative and noncooperative equilibria and their associated levels of expected welfare. What we have done is as follows. We have set $a-c=4,{ }^{21}$ and we have chosen values for the parameter $\beta$ and for a parameter $\lambda, 0<\lambda<1$, which determines the magnitude of the parameter in relation to its upper bound $\bar{\theta}(d)$. Initially we have chosen values $\beta=0.2$ and $\lambda=0$. 5. For each of the values of $d$ given in table 10.1 and for the value of $\theta=\lambda \cdot \bar{\theta}(d)$, we have solved for the following: (1) the probability of discovery per firm in the social optimum, which we denote by $\hat{p}_{i}, i=1,2$ (in doing this calculation, we take into account the fact that in the social optimum there would be full information sharing); and (2) the equilibrium levels of $\mathrm{R} \& \mathrm{D}$ spending in both the cooperative and noncooperative equilibria, which we denote by $p_{i}^{C}, p_{i}^{N}, i=1,2$, respectively (in doing these calculations, we take into account the fact that information will be shared if $\lambda \leq \breve{\lambda}(d)$ and will not be shared otherwise).

We use the convention that if one of the firms does not undertake R\&D it is always the second. We have then computed the expected levels of welfare in the social optimum and in both the cooperative and noncooperative equilibria. By definition, expected welfare in each of the two equilibria is less than the expected welfare in the social optimum. We can therefore calculate the percentage welfare loss in each of the two equilibria. These are denoted by $L^{C}$ and $L^{N}$ for the cooperative and noncooperative equilibrium, respectively. For the case where $\lambda \leq \breve{\lambda}(d)$, and so information is fully shared in both the cooperative and noncooperative equilibria, firms are making the socially optimal information-sharing decision, and so this welfare loss arises solely because firms are making the wrong $\mathrm{R} \& \mathrm{D}$ decisions. However, when $\lambda>\breve{\lambda}(d)$ firms are, in addition, making the wrong information-sharing decision. We then calculate the hypothetical level of welfare that would have arisen for the given equilibrium levels of $R \& D$ spending, but assume now that information is fully shared. Using this, it is possible to decompose the overall welfare losses into welfare losses $L_{R}^{C}$

21. Higher values of this parameter resulted in outcomes where firms were innovating almost surely most of the time, while lower values of this parameter produced very low $R \& D$ probabilities. As we will see, this parameter produces quite a wide range of $\mathrm{R} \& \mathrm{D}$ probabilities as other parameters varied. 
Table 10.2

\section{Comparison of Cooperative and Noncooperative Equilibria to} Social Optimum

$\beta=0.2, \lambda=0.5$

\begin{tabular}{llll}
\hline$d$ & \multicolumn{1}{c}{1} & 2.142 & 3.585 \\
\hline$\hat{p}_{1}$ & 0.99 & 0.659 & 0.532 \\
$\hat{p}_{2}$ & 0 & 0.659 & 0.532 \\
$p_{1}^{C}$ & 0.982 & 0.551 & 0.354 \\
$p_{2}^{C}$ & 0 & 0.551 & 0.354 \\
$L^{C}$ & 0.03 & 0.67 & 4.47 \\
$L_{R}^{C}$ & 0.03 & 0.67 & 1.55 \\
$L_{1}^{C}$ & 0 & 0 & 2.91 \\
$p_{1}^{N}=p_{1}^{N}$ & 0.899 & 0.762 & 0.57 \\
$L^{N}$ & 1.98 & 0.69 & 3.2 \\
$L_{R}^{N}$ & 1.98 & 0.69 & 0.07 \\
$L_{1}^{N}$ & 0 & 0 & 3.12 \\
\hline
\end{tabular}

and $L_{R}^{N}$ that arise in each of the two equilibria because of the wrong R\&D decisions, and welfare losses $L_{I}^{C}$ and $L_{I}^{N}$ that arise because the wrong information-sharing decision has been made.

Table 10.2 presents the calculations for three values of $d=1,2.142$, 3.585 (no extra insights are obtained by including the calculations for the other two values of $d$ ). It should be borne in mind that the associated values of $\breve{\lambda}$ are $1,0.704$, and 0.443 , respectively. So, with $\lambda=0.5$ information will be shared for the first two values of $d$, but not for the third.

A number of points emerge from this table. First, when damage is low, so too are taxes. The returns to $R \& D$ in terms of either welfare or profits are high, and this causes firms to undertake a lot of R\&D with a high probability of discovery. But this also means that the probability of duplication is also high. For this reason, in both the social optimum and the cooperative equilibrium, it pays to shut a lab. However, in the noncooperative equilibrium both labs operate, giving rise to significant losses from excessive duplication. Since, when damage is low information is always shared, the only welfare losses arise from getting R\&D decisions wrong, and the cooperative equilibrium performs significantly better than the noncooperative equilibrium.

Second, when damage is somewhat higher, so too are taxes and the returns to R\&D in terms of both welfare and profits are lower. The risk of duplication is now lower, and it turns out that in both the social optimum and the cooperative equilibrium both labs are kept open. Compared to the social optimum, the cooperative equilibrium underinvests in $R \& D$ and the noncooperative equilibrium overinvests. The losses are of almost equal magnitude. Once again information is fully shared, so the R\&D losses are the only ones that matter. 
Third, when damage is higher still, so too are taxes and the returns to $\mathrm{R} \& \mathrm{D}$ fall further, so further reducing the risk of needless duplication. Both labs are therefore always used. The noncooperative equilibrium overinvests and the cooperative equilibrium underinvests, but now the loss from underinvestment is considerably greater than the loss from overinvestment, and in terms of R\&D decision making the noncooperative equilibrium now scores better than the cooperative equilibrium. However, with this level of damage, taxes fall with $\theta$, which, ceteris paribus, raises the profits from not sharing information. Thus, in this case, information will not be shared, but, since the probability that just one firm will discover the technology is higher in the noncooperative equilibrium than in the cooperative equilibrium, the welfare loss from getting the informationsharing decision wrong is higher in the noncooperative equilibrium than in the cooperative equilibrium. Nevertheless, the difference is rather small and is dominated by the better performance of the noncooperative equilibrium in terms of $\mathrm{R} \& \mathrm{D}$ decision making. Thus the overall conclusion from table 10.2 is that RJVs outperform noncooperative equilibria when damage is low, but that this is reversed when the damage is high.

Appendix tables 10A.6-10A.8 report the results of similar exercises for various parameter values. Thus in table 10A.6, we report the outcomes when there is more rapid diminishing to returns to $R \& D$ and $\beta=0.5$. Now both labs are always kept open. Nevertheless, the conclusions of table 10.2 are broadly confirmed-RJVs do better when damage is small because overinvestment in the noncooperative equilibrium dominates the underinvestment of the cooperative equilibrium. However, the positions are reversed as damage increases.

Appendix table 10A.7 reports the outcomes when $\beta=0.2$, but now $\lambda$ is raised to 0.75 . Now information is not shared when damage takes its intermediate value, and in this case the information-sharing loss from the RJV exceeds that in the noncooperative equilibrium. Other than that, the results broadly confirm the findings of table 10.2.

Finally, appendix table 10A.8 reports the outcomes when $\beta=0.2$, but now $\lambda=0.25$. Now information is always shared and both labs are always kept open. The performance of the RJV gets steadily worse as damage increases and so too does the extent of underinvestment, whereas the performance of the noncooperative equilibrium steadily improves as the extent of overinvestment is reduced.

\subsection{Conclusion}

We have examined the performance of environmental RJVs using a model in which information sharing is endogenous, firms can choose to license their technology, and the number of labs that are operated is endog- 
enous. Welfare losses can arise through (1) the failure to make the right information-sharing decisions; (2) the failure to operate the right number of labs, leading to excessive duplication of effort; and (3) getting the R\&D decisions wrong through under- or overinvestment. We have shown that an analysis of this issue requires a careful discussion of the informational and commitment powers of the government in setting its environmental policy.

In the context of a very simple model in which there is very limited commitment, we have shown the following. First, as in Ulph and Katsoulacos (1998), RJVs will share information under precisely the same circumstances as in the noncooperative equilibrium. Second, information sharing is more likely when damage and hence taxes are low. Third, when damage is low, RJVs perform better in R\&D decision making than does the noncooperative equilibrium for two reasons: since the returns to $\mathrm{R} \& \mathrm{D}$ are high they are more likely to avoid the risk of needless duplication and the loss from underinvestment by the RJV is smaller than the loss from overinvestment in the noncooperative equilibrium. Fourth, as damage rises, the underinvestment by the RJV increases and the overinvestment in the noncooperative equilibrium falls. A tentative conclusion is that RJVs do better than noncooperative arrangements when environmental damage is low, but worse when environmental damage is high.

\section{Appendix}

Table 10A.1 Computed Values of Tax Rate, Profits, and Welfare $d=1, \bar{\theta}=1, \tilde{\theta}=1.2, \tilde{\lambda}=1$

\begin{tabular}{llll}
\hline$\theta$ & $t^{10}$ & \multicolumn{1}{c}{$\Sigma^{10}$} & \multicolumn{1}{c}{$W^{10}$} \\
\hline 0 & 25 & 1,250 & 2,500 \\
0.1 & 27.4 & $1,130.1$ & $2,384.9$ \\
0.2 & 29.6 & $1,027.4$ & $2,291.5$ \\
0.3 & 31.4 & 950.0 & $2,220.8$ \\
0.4 & 32.8 & 902.2 & $2,172.7$ \\
0.5 & 33.8 & 884.3 & $2,145.3$ \\
0.6 & 34.3 & 893.8 & $2,136.1$ \\
0.7 & 34.5 & 926.3 & $2,142.1$ \\
0.8 & 34.3 & 976.7 & $2,160.3$ \\
0.9 & 34.0 & $1,039.8$ & $2,187.9$ \\
1 & 33.3 & $1,111.1$ & $2,222.2$ \\
\hline
\end{tabular}

Note: Information shared is $\forall \theta, 0 \leq \theta \leq \bar{\theta} \Rightarrow \check{\lambda}=1$. 
Table 10A.2 Computed Values of Tax Rate, Profits, and Welfare $d=1.497, \bar{\theta}=0.7, \tilde{\theta}=0.6, \tilde{\lambda}=0.86$

\begin{tabular}{llll}
\hline$\theta$ & $t^{10}$ & $\Sigma^{10}$ & $W^{10}$ \\
\hline 0 & 39.9 & 801.9 & $2,002.4$ \\
0.07 & 41.0 & 740.9 & $1,926.4$ \\
0.14 & 41.9 & 694.1 & $1,866.4$ \\
0.21 & 42.6 & 663.3 & $1,822.3$ \\
0.28 & 43.0 & 649.1 & $1,793.1$ \\
0.35 & 43.3 & 651.4 & $1,777.8$ \\
0.42 & 43.3 & 668.8 & $1,774.9$ \\
0.49 & 43.1 & 699.5 & $1,782.7$ \\
0.56 & 42.8 & 741.6 & $1,999.7$ \\
0.63 & 42.3 & 792.7 & $1,824.1$ \\
0.7 & 41.7 & 850.7 & $1,854.6$ \\
\hline
\end{tabular}

Note: By interpolation, $\breve{\theta}=0.641 \Rightarrow \breve{\lambda}=0.916$.

Table 10A.3 Computed Values of Tax Rate, Profits, and Welfare $d=2.142, \bar{\theta}=0.5, \tilde{\theta}=0.365, \tilde{\lambda}=0.73$

\begin{tabular}{llll}
\hline$\theta$ & $t^{10}$ & $\Sigma^{10}$ & $W^{10}$ \\
\hline 0 & 52.3 & 506.5 & $1,591.3$ \\
0.05 & 52.5 & 476.9 & $1,542.7$ \\
0.1 & 52.7 & 457.4 & $1,505.0$ \\
0.15 & 52.7 & 448.1 & $1,477.8$ \\
0.2 & 52.6 & 448.8 & $1,460.4$ \\
0.25 & 52.5 & 459.0 & $1,452.2$ \\
0.3 & 52.2 & 478.1 & $1,452.2$ \\
0.35 & 51.8 & 505.3 & $1,459.7$ \\
0.4 & 51.3 & 539.5 & $1,473.8$ \\
0.45 & 50.7 & 579.7 & $1,493.5$ \\
0.5 & 50.0 & 625.1 & $1,518.1$ \\
\hline
\end{tabular}

Note: By interpolation, $\breve{\theta}=0.352 \Rightarrow \breve{\lambda}=0.704$.

Table 10A.4 Computed Values of Tax Rate, Profits, and Welfare $d=3.585, \bar{\theta}=0.3, \tilde{\theta}=0.194, \tilde{\lambda}=0.65$

\begin{tabular}{llll}
\hline$\theta$ & $t^{10}$ & $\Sigma^{10}$ & $W^{10}$ \\
\hline 0 & 67.3 & 237.8 & $1,090.5$ \\
0.03 & 67.0 & 229.3 & $1,067.7$ \\
0.06 & 67.0 & 225.8 & $1,050.2$ \\
0.09 & 66.3 & 227.2 & $1,037.7$ \\
0.12 & 65.9 & 233.2 & $1,030.1$ \\
0.15 & 65.4 & 243.6 & $1,027.1$ \\
0.18 & 64.9 & 258.2 & $1,028.2$ \\
0.21 & 64.4 & 276.6 & $1,033.3$ \\
0.24 & 63.8 & 298.5 & $1,042.0$ \\
0.27 & 63.2 & 323.6 & $1,054.0$ \\
0.3 & 62.5 & 351.6 & $1,069.0$ \\
\hline
\end{tabular}

Note: By interpolation, $\breve{\theta}=0.133 \Rightarrow \breve{\lambda}=0.443$. 
Table 10A.5 Computed Values of Tax Rate, Profits, and Welfare

\begin{tabular}{llll}
$d=$ & \multicolumn{4}{c}{$0.405, \bar{\theta}=0.1, \tilde{\theta}=0.06, \tilde{\lambda}=0.6$} \\
\hline$\theta$ & $t^{10}$ & $\Sigma^{10}$ & $W^{10}$ \\
\hline 0 & 86.8 & 38.4 & 438.4 \\
0.01 & 86.5 & 38.1 & 434.8 \\
0.02 & 86.2 & 38.7 & 432.1 \\
0.03 & 85.9 & 40.0 & 430.1 \\
0.04 & 85.5 & 42.1 & 429.0 \\
0.05 & 85.2 & 44.9 & 428.6 \\
0.06 & 84.8 & 48.4 & 428.9 \\
0.07 & 84.5 & 52.7 & 430.0 \\
0.08 & 84.1 & 57.6 & 431.8 \\
0.09 & 83.7 & 63.2 & 434.2 \\
0.1 & 83.3 & 69.4 & 437.3
\end{tabular}

Note: By interpolation, $\breve{\theta}=0.015 \Rightarrow \breve{\lambda}=0.15$.

Table 10A.6 Comparison of Cooperative and Noncooperative Equilibria to Social Optimum

$\beta=0.5, \lambda=0.5$

\begin{tabular}{llll}
\hline$d$ & \multicolumn{1}{c}{1} & 2.142 & 3.585 \\
\hline$\hat{p}_{1}$ & 0.609 & 0.47 & 0.34 \\
$\hat{p}_{2}$ & 0.609 & 0.47 & 0.34 \\
$p_{1}^{C}$ & 0.573 & 0.358 & 0.197 \\
$p_{2}^{C}$ & 0.573 & 0.358 & 0.197 \\
$L^{C}$ & 0.13 & 1.07 & 3.73 \\
$L_{R}^{C}$ & 0.13 & 1.07 & 1.61 \\
$L_{I}^{C}$ & 0 & 0 & 2.11 \\
$p_{1}^{N}=p_{2}^{N}$ & 0.665 & 0.48 & 0.31 \\
$L^{N}$ & 0.33 & 0.0 & 2.93 \\
$L_{R}^{N}$ & 0.33 & 0.0 & 0.07 \\
$L_{I}^{N}$ & 0 & 0 & 2.85 \\
\hline
\end{tabular}

Table 10A.7 Comparison of Cooperative and Noncooperative Equilibria to Social Optimum

$\beta=0.2, \lambda=0.75$

\begin{tabular}{llll}
\hline$d$ & \multicolumn{1}{c}{1} & 2.142 & 3.585 \\
\hline$\hat{p}_{1}$ & 0.996 & 0.708 & 0.595 \\
$\hat{p}_{2}$ & 0 & 0.708 & 0.595 \\
$p_{1}^{C}$ & 0.99 & 0.593 & 0.425 \\
$p_{2}^{C}$ & 0 & 0.593 & 0.425 \\
$L^{C}$ & 0.04 & 5.11 & 4.5 \\
$L_{R}^{C}$ & 0.04 & 0.99 & 1.84 \\
$L_{I}^{C}$ & 0 & 4.18 & 2.66 \\
$p_{1}^{N}=p_{2}^{N}$ & 0.942 & 0.834 & 0.658 \\
$L^{N}$ & 3.19 & 3.78 & 2.73 \\
$L_{R}^{N}$ & 3.19 & 1.39 & 0.28 \\
$L_{I}^{N}$ & 0 & 2.39 & 2.44 \\
\hline
\end{tabular}


Table 10A.8 Comparison of Cooperative and Noncooperative Equilibria to Social Optimum

$\beta=0.2, \lambda=0.25$

\begin{tabular}{llll}
\hline$d$ & \multicolumn{1}{c}{1} & 2.142 & 3.585 \\
\hline$\hat{p}_{1}$ & 0.694 & 0.552 & 0.41 \\
$\hat{p}_{2}$ & 0.694 & 0.552 & 0.41 \\
$p_{1}^{C}$ & 0.676 & 0.448 & 0.248 \\
$p_{2}^{C}$ & 0.676 & 0.448 & 0.248 \\
$L^{C}$ & 0.01 & 0.39 & 0.85 \\
$L_{R}^{C}$ & 0.01 & 0.39 & 0.85 \\
$L_{I}^{C}$ & 0 & 0 & 0 \\
$p_{1}^{N}=p_{2}^{N}$ & 0.779 & 0.599 & 0.395 \\
$L^{N}$ & 0.34 & 0.08 & 0.00 \\
$L_{R}^{N}$ & 0.34 & 0.08 & 0.00 \\
$L_{I}^{N}$ & 0 & 0 & 0
\end{tabular}

\section{References}

d'Aspremont, C., and A. Jacquemin. 1988. Cooperative and non-cooperative R\&D in a duopoly with spillovers. American Economic Review 78:1133-37.

Hinloopen, J. 1997. Research and development, product differentiation and robust estimation. Ph.D. diss., European University Institute, Florence.

Katsoulacos, Y., and D. Ulph. 1998a. Endogenous spillovers and the performance of research joint ventures. Journal of Industrial Economics 46:333-57.

. 1998b. Innovation spillovers and technology policy. Annales d'Economies et Statistiques 49/50:589-607.

Katsoulacos, Y., and A. Xepapadeas. 1996. Environmental innovation, spillovers and optimal policy rules. In Environmental policy and market structure, ed. C. Carraro, Y. Katsoulacos, and A. Xepapadeas, 143-50. Dordrecht: Kluwer.

Petrakis, E., and J. Poyago-Theotoky. 1997. Environmental impact of technology policy: R\&D subsidies versus R\&D cooperation. University of Nottingham Discussion Paper no. 97/16.

Poyago-Theotoky, J., ed. 1997. Competition, cooperation, research and development. New York: Macmillan.

Scott, J. T. 1996. Environmental research joint ventures among manufacturers. Review of Industrial Organisation 11:655-79.

Ulph, A. 1996a. Environmental policy and international trade when governments and producers act strategically. Journal of Environmental Economics and Management 30:265-81.

. 1996b. Strategic environmental policy. In Environmental policy and market structure, ed. C. Carraro, Y. Katsoulacos, and A. Xepapadeas, 97-127. Dordrecht: Kluwer.

Ulph, A., and D. Ulph. 1996. Trade, strategic innovation and strategic environmental policy-A general analysis. In Environmental policy and market structure, ed. C. Carraro, Y. Katsoulacos, and A. Xepapadeas, 181-208. Dordrecht: Kluwer.

Ulph, D. 1994. Strategic innovation and strategic environmental policy. In Trade innovation, environment, ed. C. Carraro, 205-28. Dordrecht: Kluwer.

- 1997. Environmental policy and technological innovation. In New direc- 
tions in the economic theory of the environment, ed. C. Carraro and D. Siniscalco, 43-68. Cambridge: Cambridge University Press.

Ulph, D., and Y. Katsoulacos. 1998. Endogenous spillovers and the welfare performance of research joint ventures. University College London. Mimeo.

\section{Comment Jerome Rothenberg}

The authors examine the performance of environmental RJVs in an extremely rich analytical context, drawing together several important issues - environmental damage, government taxes, industry competitiveness, information sharing, and government policy toward cooperative research and development (R\&D) behavior of environmental, growth, and regulatory economics. They do this with clarity and skill. Theirs is a very illuminating treatment.

They are rewarded with most interesting results. It is important that in their complex set of relationships there is no general answer to the question of whether environmental policy abets or hinders the performance of RJVs. What transpires is that for some combinations of parameter values the effort is positive, for others negative. But the results have intuitive thrust. Thus, we have an opportunity to see how the different portions of the model generate trade-offs and how these trade-offs are mediated by other portions of the model. The interconnectedness of parts becomes, in effect, the centerpiece of the exercise. And the reader's exercise of intuition in the system is most useful for understanding what such a system is really like. In particular, the disparate forces acting on social welfare become appreciated more fully.

The overall system is quite complex due to the variety of market failures that are embedded, and against which the performance of environmental policy and RJVs is evaluated. To render such a system reasonably tractable, a number of stringently simplifying assumptions are adopted. These make it possible to have enough transparency to understand intuitively the great variety of complex outcome scenarios. Greater complexity would risk this transparency, but I should like to venture to ruminate about some analytic avenues that have been precluded that would have permitted the inclusion of what I believe to be important dimensions of the real world. My remaining comments will sketch these dimensions and preliminary rudiments of how they might be incorporated in the present model.

The areas I will deal with are (1) the dimensionality of R\&D, (2) the multiperiod gestation of $R \& D$ effects, and (3) various significant initial and achieved differences among firms.

Jerome Rothenberg is professor emeritus of economics at the Massachusetts Institute of Technology. 


\section{The Dimensionality of R\&D}

Level and "Angle"

The paper treats all R\&D payoffs as improved emissions controls that are perfect substitutes for one another. Firms can engage in different levels of R\&D spending, but there are only two kinds of payoffs: success or failure. The spending levels influence only the probability of success, but not its degree or character. All successes result from the same sort of new information and are perfect substitutes for one another.

An important fact about the real world is that in the face of the uncertainty represented by the problem of changing current technology so as to accomplish particular new goals, different researchers and research organizations will often try different approaches to the problem (the history of science is replete with this phenomenon). Moreover, especially where competitive market-oriented efforts are involved, these different routes will be deliberately kept secret from one another, notably in prepatent stages. So they are likely to have different kinds of failures and successes. The breakthroughs will generally be different. The resulting emissions improvements will therefore not usually be perfect substitutes for one another, either in amount or in kind. They will be variously imperfect substitutes. Over any one stretch of multifirm R\&D behavior, there is likely to be a spectrum of emissions improvements - although all will be comparable in terms of the achieved degree of emissions decrease per unit of market product.

To facilitate the analysis, I propose to simplify this situation drastically. I suppose that at any point in time there exists a consensus about the identity of the most conventional breakthrough route. Let this route be the point of departure for classifying all other possible kinds of breakthrough. The others are less obvious, riskier, and more controversial, both with regard to the probability of any success and the probability distribution of extent of possible successes. Assume, then, that the most conventional, least controversial direction represents the $R \& D$ route with given mean and least variance of net gains (value of gross gains less cost of the R\&D effort). Assume also that the other routes can be accorded at least an approximate net gain mean and variance, both mean and variance increasing with degree of unconventionality.

Let each $\mathrm{R} \& \mathrm{D}$ project be defined in the two dimensions of size-level of spending, $r$, and degree of unconventionality, which I call the research angle, $\alpha$ :

$$
R_{i}=\left(r_{i}, \alpha_{i}\right),
$$

where $\left(r_{i}, \alpha_{i}\right)$ defines a probability distribution of emissions-decrease outcomes from zero upward.

At any given time there exists the scientific know-how for formulating 
$n+1$ different research directions, forming a boundary set. ${ }^{1}$ Each $\left(r_{x}, \alpha_{x}\right)$ defines a different probability distribution of emissions decreases with the property that both mean, $M_{\Delta \mu}$, and variance, $\mu_{\Delta \mu}^{2}$, of outcome increase with research angle, the degree of unconventionality. These distributions are not simply multiples of $r_{x}$, since the different research angles are likely to have different scale economies.

Thus, associated with each choice of $(r, \alpha)$ is a stochastic outcome, $\Delta e$, reflecting the particular distribution relevant to that project-where $\Delta e$ is the emissions decrease achieved by that project. The larger $\alpha_{x}$, the greater is the probability that actual $\Delta e$ will be zero, but also the greater is the expected value of gain. For the analysis of firm decision making, these physical outcomes can be used both where purely regulatory goals have to be met-in terms of minimizing research and penalty costs for achieving regulatory standards - and where emissions decreases have unit monetary value - in terms of maximizing net financial gains from research.

In the present context, we apply this two-dimensional $\mathrm{R} \& \mathrm{D}$ approach by supposing that there are several $(\mathrm{m})$ firms in this industry and that they have different risk preferences in the relevant period. Then they will choose different $\left(r_{x}, \alpha_{x}\right)$, with both the level and angle different. As a result, these projects, $\left(r_{1}, \alpha_{1}\right),\left(r_{2}, \alpha_{x}\right), \ldots,\left(r_{m}, \alpha_{x}\right)$, will result in different levels of achieved emissions decreases. Moreover, since R\&D outcomes are all stochastic, even an identical set of projects by all firms would result, in the absence of information sharing, in a particular period of real time, in different achieved degrees of emissions decreases.

\section{Substitutability of R\&D Outcomes}

Increasing the dimensionality of $R \& D$ has important implications for the nature of the substitutability of R\&D outcomes. R\&D always leads to stochastic outcomes. But these are influenced by the choice of both $r$ and $\alpha-r$ as a scale factor and $\alpha$ as the particular direction and strategy by which it is hoped that research breakthroughs occur. Choice of $\alpha$ is the choice of the channel by which new knowledge is sought. In effect, it is the kinds of research issues that it is hoped will prove productive. Two firms selecting the same $\alpha$, however different their research scales $\left(r_{1}, r_{2}\right)$, will be on the same route, manipulating and discovering new knowledge of the same sort. Whatever research results transpire will be quite similar-even though the firm with smaller scale is not likely to have gone as far in discovery. Thus, the efforts of the smaller research project will carry little of interest to the larger project; the interest of the smaller in the larger will be primarily to find out how much further one can probably get to by continuing in the same direction. Thus, their results are highly substitu-

1. The set of directions that, for each variance, has the highest mean R\&D outcome. Given the heterogeneous risk preferences, this represents the only set of inherently nondominated directions. 
tive-each having little to learn from the other in that part of their quest with which both have experience.

Say, instead, that the two firms have chosen the same $r$ and very different $\alpha,\left(\alpha_{1}, \alpha_{2}\right)$. Now they are setting out on very different tasks, dealing with different analytical issues and different strategies-although both aimed at the same final achievements, new technology for emissions reductions. Whatever results they stochastically achieve, they will have come by via different kinds of new knowledge. As when viewing statuary, you learn more about a statue by walking around it than by staring at it from a single perspective. Two $R \& D$ ventures with these different $\left(\alpha_{1}, \alpha_{2}\right)$ will teach a lot more about the natural systems involved than two $R \& D$ ventures with the same $\alpha, \alpha_{1}=\alpha_{2}$. The former outcomes will not be substitutive, but complementary.

Generalizing, then, firms can influence the degree of substitutability or complementarity of their R\&D results with those of other firms by their choice of similar or different relative to the others. Moreover, the degrees, as well as the sign, of outcome relatedness can vary substantially depending on the specific differences in chosen research direction.

We discuss later why degree and sign of relatedness are quite important for the issues taken up in this paper-notably, sharing of information and/ or coordinating research efforts across firms.

\section{R\&D as a Multiperiod Process}

The second major issue concerns the temporal dynamics of R\&D. A firm's R\&D commitment does not involve a single time-span effort after which the $R \& D$ is either attained or fails. The character of an $R \& D$ effort is often set by the nature of environmental regulation. Often the regulation specifies "ultimate" emissions control goals not presently attainable, along with a timetable of steps for gradually meeting them. Experience leads to the expectation that it will take a number of breakthroughs, not one, to achieve the goals. A particular R\&D strategy $(\alpha)$ is a game plan for passing through a sequence of research efforts to reach the ultimate goals. Each $\mathrm{R} \& \mathrm{D}$ stage is expected to advance the search, but not end it.

Accordingly, R\&D projects have intermediate effects-new understanding about technological processes and newly revised prospects for success. Future success depends on this new information and these successes so far. Choice of $\alpha$ at the outset is thus a strategy for generating an intermediate new understanding that will be productive for additional gains in the further future. Moreover, this further progress may depend on the willingness to combine this new information with that of intermediate new information generated by $\mathrm{R} \& \mathrm{D}$ in other firms. The potential research productivity of such combining depends on the degree of complementarity of such new intermediate understanding. R\&D projects using nearly similar $\alpha$ will produce new information that is very much alike, and therefore not 
very productive for future progress. But projects with very dissimilar $\alpha$ s, exploring quite different aspects of the problem, are likely to generate intermediate results that are not only different but mutually enlightening, and thus with a high potential for productivity in combined efforts.

Thus, the impetus for either sharing research results along the way, or actually combining future efforts jointly, is influenced importantly by the choice of $\alpha$ at the outset of the R\&D commitment. The key is complementarity of results - that is, nonsubstitutability. Indeed, degree of complementarity is appropriately defined in terms of extent of potential fruitfulness of combined, or shared, R\&D efforts. Complementarity now makes future joint projects, or sharing of results (leasing), potentially attractive.

Therefore, the incentives for information transfer and/or RJV, and thus for an optimal new technology transfer, are directly related to the deliberate strategic choice of $\alpha$, not merely of $r$. This relevance of $\alpha$ is expressly in the context of intertemporal, multiperiod innovation strategy.

The degree of interfirm informedness is important in this. Two extreme cases can be distinguished. In the first, no firm knows the $\alpha$ choice, and intermediate outcomes, of any other firm. Generally, each will know about the others only after new processes have been patented. This is plausible. The relevant information is highly proprietary, and firms strive to keep it secret. At the other extreme, every firm knows the $\alpha$ choices and intermediate results of all the others. The first case seems a much closer approximation to the truth. In such a situation, period-by-period R\&D behavior by itself will have an important element of strategy about the attractions of future jointness in continuing efforts. As an example, the persistent choice of $\alpha$ near $\alpha_{0}$ (a low-risk strategy) represents playing it safe. Such a firm will not be signaling a desire to initiate joint efforts with the other firms having very different $\alpha$ from theirs. It might subsequently be passively receptive to sharing or coordination with significantly nonconsensual efforts differing from its own markedly, but its low-risk propensities suggest that this would represent a gambling endeavor foreign to those propensities. On the other hand, a firm choosing a highly nonconsensual direction would probably be risk-preferring. It is likely to be signaling willingness both to share information-or even more, to collaborate with other firms selecting high but very different values of $\alpha$-and also to accept such initiatives from other risk-preferring firms.

The impact of this strategic variable on leasing or RJV requires looking more richly at the R\&D situation. In particular, we must know something about the initial similarities or differences between the two firms in their emissions rates per unit output.

Case 1. The two firms (F1 and F2) begin with very different emissions rates, but choose the same $\alpha$. The firm with less prior R\&D success (say F2) could gain here from a catch-up strategy by sharing F1's information. But F1 would gain little from such sharing, since F2 has little of interest 
for it. So only leasing by F1 to F2 is likely-and only on tough profitmaximizing terms.

Case 2. The initial difference in emissions rates for $\mathrm{F} 1$ and $\mathrm{F} 2$ is small, but the difference of the chosen $\alpha$ is large. The big strategy difference here suggests highly complementary R\&D output. On the basis of pre-R\&D technology, this complementarity would not make sharing or coordination attractive to either firm at the outset of R\&D. But it makes future interchange probable. Since R\&D is a multistage process, the large difference in $\alpha$ suggests that first-stage outcomes will be quite different for the two firms. In such a situation, their complementarity will be favorable for interchange.

The first two cases focus on firm differences in $\alpha$ and emissions rates. But the absolute strategy direction of each firm and the size of first-stage R\&D outcomes matter as well.

Case 3. F1 has a high $\alpha$, that is, is highly unconventional. It represents a high-risk strategy, carrying possibilities of large gains. Since much lower $\alpha$ strategies are likely to be adopted by other firms, F1 will have R\&D outcomes that are highly complementary with those of many other firms. If its first-stage successes are meager, it will be anxious to share with more successful firms; but such interchange may well have little attraction for those firms. On the other hand, if it has important first-stage successes, its unique types of new information will be very attractive to other firms, successful or not. Moreover, the prospect of really major success from interchange with other complementary firms will make this firm seek sharing. So high risk taking may well signal a predisposition to share information.

Case 4. F1 and F2 adopt strategies that make their R\&D results sufficiently complementary. If their $\mathrm{R} \& \mathrm{D}$ outcomes in the first stage are poor, they are likely to have little interest in sharing. Similarly, if both have nearly equal success in the first stage, their incentive to share is not likely to be great. But a large disparity in successful outcomes may well make the less-successful firm eager to share. If the strategy of F1, the lesssuccessful firm, is one of high risk, the successes may well induce F2, the more-successful firm, to share, on the chance that their complementarity, fed by the moderate success of F1, could generate a large overall success due to the large stakes being pursued by F2.

These speculations suggest that in a multistage conception of the R\&D process, initial and midcourse behavior depends on stochastic outcomes during the process, in the context of the strategic directions chosen by the various firms involved. 


\section{Asymmetries among Firms}

Real-world firms have differences that are important to the issues dealt with in the paper. We have already suggested that differences in risk preferences will lead them to choose differently with respect to $R \& D$, not only in whether or not they engage in $\mathrm{R} \& \mathrm{D}$, individually or cooperatively, but also in how they invest in R\&D, with regard to both level and angle. These differences create distinctive trajectories over time. Indeed, because the R\&D process is inherently stochastic, they are likely to have different temporal trajectories even if they make identical choices at each time, although these differences will be smaller and less systematic than due to the former source.

But there are other systematic sources of difference as well: initial conditions. At any moment of time, firms in the same industry will generate different rates of emissions per unit of output due to historical differences in technology, in capital stock, in capital-output ratios, and in different vintages. Moreover, these emissions generate different unit damages. They have different locations, and these influence the size of damages because of differences in potential victim populations, density, and the assimilative capacity of the relevant local environments.

If environmental policy is used to maximize social welfare, then (1) firms with equal social-damage functions will be taxed (or otherwise regulated) to generate the same marginal trade-off between environmental impairment and net economic gain from market activities, and (2) firms with different social-damage functions will be taxed (or otherwise regulated) for different environmental and market trade-offs. In the presence of the two kinds of firm differences mentioned, both cases lead to different firms facing different required environmental performance for optimal performance compliance. If firms with similar damage functions are faced with regulation with the same final emissions-rate goal, then some will start with less far to go and others with farther to go to reach it. For some, adjustment to compliance will be easier, for others harder. Similarly, firms with different damage functions will face different degrees of difficulty in ultimate compliance.

These differences are pervasive in the real world and important. Indeed, the popularity of emissions trading in environmental policy is an explicit assertion of the importance of such interfirm differences; in their absence the policy would be meaningless.

The paper being reviewed minimizes such differences for purposes of tractability, but elaborations of such an analysis to bring the examination closer to the real world seem to warrant a compact treatment of these differences. Such a treatment is especially compatible with a multiperiod conception of $\mathrm{R} \& \mathrm{D}$ behavior.

In any stage of preparing for ultimate compliance, therefore, firms will confront one another with different requirements and opportunities, stem- 
ming from both their initial advantages and disadvantages, and the differential progress they have already made up to the present stage (and by different routes) via their $R \& D$ strategies and stochastic outcomes. This complex of differences certainly affects what decisions they will make about the next-stage strategies and actions. Symmetry will be a less relevant analytical predictor here, and bargaining power will differ from firm to firm. In such a context, leasing and trading schemes may become more important and RJVs less so, because the former have a more impersonal way of monetizing differences, while the latter must achieve monetization of these differences by personal negotiation and are embedded in the very structure of the more integral cooperation.

\section{Competition and Competitive Advantage}

The degree of competitiveness in an industry, as influence on and influenced by the various factors concerning $R \& D$, is treated as having an influence on social welfare. It would be useful to bring together the impacts on the meaning and measure of competitive market advantage of the kinds of modifications I have been discussing here.

Given the multiperiod R\&D framework, let us assume that full gestation to ultimate compliance from the outset involves a long time period. Then the regulator is likely to set stage-by-stage deadlines for achieving interim standards. If so, most R\&D improvements would be implemented nearly as soon as they emerge, instead of being saved up until they could lend their insights and R\&D experience to find ultimate $R \& D$ success on the most efficient path fed by trial and error. Likewise, new technology leased from others would be implemented steadily as it is acquired, with acquisition not awaiting the final perfection of outcomes in the particular direction of change.

Then the cost of acquiring these improvements would be annualized into firms' operating costs, and the resulting operating cost structures would affect the competitiveness of the various firms. Our discussion lends itself to the strong expectation that firms will differ substantially in these new technology costs, deriving from differences in firms' initial conditions, differential regulatory treatment, and differential R\&D strategy and success. So environmental policy, in such a context, can lead to nontrivial changes in interfirm market power, with possibly further influence on market structure.

How these changes will play out against the outcomes in other dimensions of the complex system we have been discussing is far more likely to evade precise delineation than in our authors' worthy, far tidier model. But in what must be at least a highly speculative judgment, I must concur with the authors that the most useful attitude to adopt at the present about RJVs is skepticism. 